\title{
O Programa Nacional de Formação de Professores - PARFOR em uma Universidade Comunitária: impactos e resultados
}

\author{
The National Plan for Training Teachers of the Basic Education \\ - PARFOR in a Community University: impacts and results
}

\author{
Rafael Ângelo Bunhi Pinto ${ }^{1}$ - ${ }^{1}$ Universidade de Sorocaba | Programa de Pós-Graduação em \\ Educação | Sorocaba | SP | Brasil. Contato: rafael.pinto@ prof.uniso.br. ORCID: \\ http://orcid.org/0000-0003-4988-3628
}

Waldemar Marques ${ }^{2}$ - ${ }^{2}$ Universidade de Sorocaba | Programa de Pós-Graduação em Educação | Sorocaba | SP | Brasil. Contato: de41marques@ gmail.com. ORCID: http://orcid.org/0000$\underline{0002-6353-6289}$

Leo Victorino da Silva ${ }^{3}{ }^{3}$ Universidade de Sorocaba | Centro de Educação e Tecnologia | Sorocaba | SP | Brasil. Contato: leo.silva@prof.uniso.br. ORCID: http://orcid.org/0000-0002$\underline{4051-3551}$
Resumo: A partir da década de 1990, há no Brasil uma preocupação maior em torno de políticas públicas, em razão das várias transformações advindas da globalização e do neoliberalismo, bem como da reforma do Estado, que impactaram diretamente a educação. O presente trabalho analisa e avalia a implementação, o desenvolvimento e os resultados da política pública de formação de professores - Parfor em uma Universidade Comunitária, localizada no município de Sorocaba/SP. O Parfor é resultado de ações do Ministério da Educação em colaboração com secretarias estaduais e municipais de educação e Instituições de Ensino Superior com o objetivo de ministrar cursos superiores de licenciatura gratuitos e de qualidade a professores em exercício nas escolas públicas sem formação adequada à Lei de Diretrizes e Bases da Educação. Especificamente na Universidade de Sorocaba, a experiência inovadora da implementação do Parfor permite constatar a relação da Instituição com as comunidades local e regional, o compromisso com a educação e os resultados de suas práticas e de seus serviços voltados para essas comunidades, principalmente no que se refere à formação de docentes e outros profissionais da educação básica. Aponta também este artigo os limites e dificuldades de uma ação deste tipo destinada à formação docente.

Palavras-chave: Políticas educacionais. Formação docente. PARFOR.

\begin{abstract}
Since the 1990s, there is a greater concern in Brazil regarding public policies, due to the various transformations resulting from globalization and neoliberalism, as well as state reform, which directly affected education. This paper aims to analyze and evaluate the implementation, development and results of the public policy of teacher education - Parfor in a Community University, located in the City of Sorocaba, State of São Paulo. Parfor is the result of actions by the Ministry of Education in collaboration with state and municipal education offices and higher education institutions to provide free and quality undergraduate courses to public school teachers without adequate training in the Education Guidelines and Bases Law. Specifically at the University of Sorocaba, Parfor's innovative implementation experience shows the institution's strict relation with local and regional communities, its commitment to education and the results of its practices and services related to teaching, research and outreach aimed at these communities, particularly regarding the training of teachers and other professionals of basic education in Sorocaba and its region. This article also points out the limits and difficulties of an action of this type aimed at teacher training.
\end{abstract}

Keywords: Educational policies. Teacher training. PARFOR.

Recebido em: 3 março de 2020 • Aprovado em: 21 de outubro de 2020

DOI: http://dx.doi.org/10.1590/S1414-40772020000300013

Este é um artigo publicado em acesso aberto sob uma licença Creative Commons

https://creativecommons.org/licenses/by-nc/4.0/ 


\section{Introdução}

Este artigo tem como objetivo analisar e avaliar a implementação, o desenvolvimento e os resultados da política pública de formação de professores - Parfor em uma Universidade Comunitária, localizada no município de Sorocaba/SP. A metodologia utilizada foi a da pesquisa avaliativa que, segundo Belloni, Magalhães e Sousa (2001), é centrada na análise da adequação e relevância de políticas, programas ou projetos, com objetivos e metas explícitos, e com a finalidade de identificar os fatores que favorecem ou impedem seu desenvolvimento. Quanto aos métodos utilizados, eles envolveram a pesquisa bibliográfica e o estudo de caso, referente à implantação e ao desenvolvimento do Parfor na Universidade de Sorocaba.

\section{A herança}

A preocupação com a educação e, em decorrência, com a educação básica, principalmente no que envolve a formação de professores, aparece como uma questão importante na sociedade brasileira, em razão das demandas de docentes, dirigentes e gestores educacionais, das secretarias estaduais e municipais de educação, associações e órgãos representativos de docentes, dentre outros.

Estas fortes demandas contemporâneas referentes à formação docente são caudatárias de um déficit histórico no país de Políticas de Estado voltadas à construção de um sistema educativo verdadeiramente republicano, comprometido com a construção de uma sociedade democrática. No período colonial, a educação não ultrapassava umas poucas unidades de ensino distribuídas pelo território brasileiro em formação, administrada pelos jesuítas. Nessa educação, estava incluída apenas $0,1 \%$ da população; mulheres e negros escravos que constituíam $90 \%$ da população estavam condenados às trevas do analfabetismo (RISTOFF; BIANCHETTI, 2012, p. 792). As mudanças na educação foram muitas, seguindo os diferentes períodos históricos pelos quais passou o país no império, adentrando até a primeira República. Ampliou-se a oferta do ensino básico, criaram-se escolas superiores; o surgimento das universidades teve de esperar mais tempo, só vindo a surgir nos anos 20 e 30 do século passado. Com isto, a expansão da educação básica se viu altamente prejudicada pela falta de formação de professores. Na conjuntura atual, os déficits de professores se deve em grande parte à ausência de políticas públicas de formação docente em quantidade e qualidade que as mudanças por que passou o país requeriam. Se hoje, em decorrência das grandes mudanças econômicas, políticas e sociais pelas quais o país passou, o Brasil é tido como uma das maiores economias do mundo, os déficits educacionais ainda persistem e os principais 
problemas que afetam essa área ainda não foram equacionados; o país se configura, assim, como um gigante "manquitola".

Essas demandas fazem surgir, no campo educacional, a necessidade de políticas públicas para a formação de professores. Embora a demanda por formação de professores fosse prioritariamente para a educação básica, a ação do poder público deu ênfase à formação de professores para a educação superior, com a criação da Coordenação de Aperfeiçoamento de Pessoal do Ensino Superior (CAPES), em 1951, segundo Ristoff e Bianchetti (2012, p. 800), “exemplo de uma vigorosa política pública direcionada ao ápice da pirâmide do sistema educacional".

A grande demanda por professores para o ensino básico só viria a ser atendida por instituições particulares de ensino superior, as Faculdades de Filosofia, Ciências e Letras isoladas, a partir dos anos 70 do século passado, à revelia de uma política pública especificamente destinada a esse fim. $\mathrm{O}$ fato é que, em decorrências das políticas voltadas à educação, nos inícios do século XXI, o Brasil alcançava o $15^{\circ}$ lugar no ranking mundial de produção científica, enquanto que, em relação à educação básica, alcançava a $50^{a}$ posição! Evidenciava-se, assim, ao se iniciar novo século, um verdadeiro "apartheid" entre a educação superior e a educação básica (RISTOFF; BIANCHETTI, 2012, p. 804).

Um dos pilares desse "apartheid" estava justamente na demanda e oferta de professores, conforme atestara o relatório do Conselho Nacional de Educação publicado em 2007, que apontava uma carência de 246 mil professores nas áreas de ciências básicas e matemática (RISTOFF; BIANCHETTI, 2012, p. 806). Passou-se mais de meio século, desde a criação da CAPES, para que o poder público se decidisse a enfrentar essa situação mediante a criação de uma nova CAPES, desta vez voltada à educação básica, com foco na formação de professores para esse nível de ensino (Lei No 11.502, de 11 de julho de 2007).

Essa nova atuação do poder público passa a se configurar como Políticas de Estado, ainda que ocorram no âmbito de um governo específico, num período de tempo delimitado, com coloração ideológica própria. Atuam mais no longo prazo e envolvem problemas que geram demandas maiores do país, e sua implementação envolve os estados e municípios. São aprovadas no âmbito do poder legislativo central, geralmente após processo de audiências públicas, com a participação de entidades representativas da sociedade. Já as Políticas de Governo envolvem decisões do poder executivo tomadas diante de determinadas demandas mais imediatas que surgem da própria agenda política e administrativa interna ou de eventos que ocorrem em âmbito externo ao país e, até mesmo, por força de conjunturas internacionais. Políticas de governo podem, mesmo, estar relacionadas ao atendimento de interesses de 
pequenos grupos e interesses partidários. É o que ocorre com frequência no Brasil, quando os valores republicanos cedem lugar aos interesses dos grupos de poder do momento.

\section{O Programa Nacional de Formação de Professores da Educação Básica - PARFOR}

Decisões de governo, relativas à educação, sinalizam o grau de importância atribuída a esse setor da ação governamental. O modo como essas decisões são tomadas e implementadas em determinados contextos, a maneira como são colocadas em ação e seu grau de articulação com políticas mais amplas, oferecem indícios da sua adequação e informam sobre o tipo de impacto que poderão ter, à luz do conhecimento já acumulado acerca do desenvolvimento de políticas e programas governamentais (GATTI, BARRETO; ANDRÉ, 2011).

Assim, temas como "políticas públicas educacionais" e "formação de professores" começaram a ganhar cada vez mais destaque nas agendas governamentais, principalmente em razão das ações que vêm sendo desenvolvidas para a melhoria da qualidade da educação mediante o aprimoramento das práticas docentes, profissionalização e valorização da carreira docente.

É o caso do Parfor, que foi criado no âmbito do Plano de Ações Articuladas - PAR, elaborado a partir do Plano de Metas e Compromisso Todos pela Educação, programa estratégico do Plano de Desenvolvimento da Educação (PDE), que busca a avaliação e implementação de políticas públicas de melhoria da qualidade da educação, sobretudo da educação básica pública. Dentro do PAR, deve-se realizar um diagnóstico da situação educacional dos estados, Distrito Federal e municípios, estruturado em quatro grandes dimensões: 1. Gestão Educacional; 2. Formação de Professores e dos Profissionais de Serviço e Apoio Escolar; 3. Práticas Pedagógicas e Avaliação; e 4. Infraestrutura Física e Recursos Pedagógicos (BRASIL, 2019).

De acordo com a CAPES (2019), o Parfor:

[...] visa induzir e fomentar a oferta de educação superior, gratuita e de qualidade, para profissionais do magistério que estejam no exercício da docência na rede pública de educação básica e que não possuem a formação específica na área em que atuam em sala de aula.

Inicialmente, essas ações foram desenvolvidas de forma colaborativa, entre os governos federal, estaduais e do Distrito Federal e municipais, com as secretarias de educação e Instituições Públicas de Educação Superior. No entanto, nos últimos anos, merece destaque a abertura da possibilidade de participação das Universidades Comunitárias nas políticas públicas voltadas para a Educação, para oferecimento de cursos e programas de educação superior, como o Parfor. As Universidades Comunitárias se enquadram em uma categoria de 
Instituições de Educação Superior não públicas e nem estritamente particulares, sem finalidades lucrativas, apresentando forte apelo social no ensino, na pesquisa e na extensão, voltados para as comunidades em que estão inseridas. Essas Instituições são geridas pela comunidade a que pertencem e são fortemente comprometidas com a responsabilidade social e com a formação de cidadãos críticos e reflexivos, nas mais diversas áreas, e não só com a formação para o mercado de trabalho (FRANTZ; SILVA, 2002; VANNUCCHI, 2004). Atualmente, as Universidades Comunitárias são legalmente amparadas pela Lei $\mathrm{N}^{\circ}$ 12.881/2013, que dispõe sobre a definição, qualificação, prerrogativas e finalidades das Instituições Comunitárias de Educação Superior - ICES, disciplina o Termo de Parceria e dá outras providências.

Em 2009, por meio do Decreto $N^{\circ} 6.755 / 2009$, o Ministério da Educação instituiu a Política Nacional de Formação de Profissionais do Magistério da Educação Básica atribuindo à Coordenação de Aperfeiçoamento de Pessoal de Nível Superior - CAPES a responsabilidade no fomento a programas de formação inicial e continuada de professores. Esse Decreto foi posteriormente revogado pelo Decreto $N^{\circ} 8.752 / 2016$, o qual manteve a essência da Política, agora denominada Política Nacional de Formação dos Profissionais da Educação Básica.

Essa Política Nacional, dentre alguns de seus objetivos, visa instituir o Programa Nacional de Formação de Profissionais da Educação Básica, o qual deverá articular ações das Instituições de Ensino Superior - IES vinculadas aos sistemas federal, estaduais e distrital de educação, por meio da colaboração entre o Ministério da Educação, os Estados, o Distrito Federal e os Municípios, para induzir avanços na qualidade da educação básica, ampliando as oportunidades de formação dos profissionais do ensino e garantir a apropriação progressiva da cultura, dos valores, dos conhecimentos e práticas, de modo a promover as aprendizagens adequadas às etapas ou às modalidades cursadas pelos estudantes.

Também busca, como estratégia, apoiar a oferta e a expansão de cursos de formação inicial e continuada para profissionais da educação básica em exercício, pelas instituições de ensino superior em diferentes redes e sistemas de ensino, conforme estabelecido pela Meta 15 do Plano Nacional de Educação - PNE (BRASIL, 2016).

Em 2009, foram oferecidos, pelo Parfor, tanto cursos de formação inicial quanto de formação continuada, nas modalidades presencial e a distância. De acordo com Filizola (2012), o Parfor, "em sua primeira edição, abriu 140 turmas em 32 instituições de educação superior, em um total de 4.273 matrículas". 
Em 2011, a formação continuada passou a ser oferecida dentro da Rede Nacional de Formação Continuada - Renafor. Em 2012, todos os cursos oferecidos na modalidade a distância passaram para a responsabilidade da Universidade Aberta do Brasil - UAB, ficando o Parfor responsável exclusivamente pelos cursos de formação inicial presencial, de primeira licenciatura, de segunda licenciatura ou de formação pedagógica (BRASIL, 2013).

As ações desenvolvidas pelo Parfor se dão em regime de colaboração da União, estados, Distrito Federal e municípios com a Capes e as IES participantes. Em 2009, apenas as IES públicas podiam participar do Parfor, mas, em 2010, por força do Decreto $\mathrm{n}^{\circ}$ 7.219/2010, permitiu-se também a participação de instituições privadas e comunitárias. Com essa possibilidade, 52 novas Instituições de Ensino Superior receberam recursos financeiros do Parfor em 2010. Dessas, 44\% eram particulares/comunitárias, 37\% federais e 19\% estaduais (SOUZA, 2014).

Para o oferecimento de turmas pelo Parfor, os cursos poderiam seguir o mesmo Projeto Pedagógico das turmas regulares do curso de Pedagogia da IES responsável pelo Curso ou ter Projeto Pedagógico próprio em atendimento às especificidades de determinada região ou ao perfil do público-alvo. Esse Projeto deveria ser encaminhado à Capes, quando do início das turmas, e elaborado considerando os princípios definidos na Política Nacional de Formação de Professores da Educação Básica. A abertura de turmas nos cursos oferecidos no âmbito do Parfor se dá mediante o mínimo de 30 alunos matriculados.

Os cursos ofertados e as IES deveriam estar em conformidade com os padrões mínimos de qualidade definidos no Sistema Nacional de Avaliação da Educação Superior SINAES. Vale lembrar que, no SINAES, os cursos e instituições são avaliados mediante conceitos numa escala que varia de 1 a 5 , sendo 1 o pior conceito e 5 o melhor, aceitando-se como padrão mínimo de qualidade o conceito 3. Ainda, os cursos não podem extrapolar o prazo de 10 semestres para integralização das turmas.

A operacionalização do Parfor é definida por meio de Edital específico. Em síntese, há a divulgação dos cursos e vagas por estados e munícipios que demandam por formação de docentes da educação básica e, posteriormente, as IES interessadas cadastram suas propostas de cursos em um sistema específico. Após essa fase, os professores da educação básica da rede pública realizam sua pré-inscrição em plataforma específica, preenchendo seu currículo e indicando o curso e o turno em que desejam estudar. Encerrado esse processo, é aberto o prazo para que as Secretarias Estaduais, do Distrito Federal e Municipais validem ou não as pré-inscrições dos candidatos. A relação dos validados e dos não validados é disponibilizada em seguida para as Instituições que tiveram suas propostas aprovadas. Após aprovação em 
Processo Seletivo, caso se faça necessário, os candidatos aprovados devem realizar suas matrículas na IES, e a Capes abre sistema específico para que essas Instituições preencham o instrumento de repasse de recursos, bem como registrem os docentes dos cursos e os profissionais da educação básica da rede pública matriculados.

Além dos recursos de custeio e de capital, o Parfor fornece bolsa da CAPES aos coordenadores gerais e adjuntos (se necessário), aos coordenadores de cursos e aos professores que ministram aulas ou fazem orientação no Parfor.

Ao analisar o Parfor na ótica de uma política pública, Pessoa e Araújo (2013, p. 17) apontam que:

\begin{abstract}
A formação docente é parte essencial da política educacional e deve ser pensada como direito social de educadores e educandos. Ordena-se pelo acesso dos profissionais da educação à formação e à profissionalização e pelo direito do aluno de aprender com profissionais que possuam as competências e habilidades próprias do processo de ensinar. Portanto, é função do estado e da sociedade garantir o acesso dos professores a uma formação de qualidade que atenda às necessidades do processo formativo de todos os cidadãos.

Essa garantia de acesso é alcançada por meio de políticas públicas efetivas, formuladas a partir de programas e ações que garantam igualdade de oportunidades.
\end{abstract}

Nesse contexto, pode-se considerar o Parfor como política pública redistributiva. As políticas públicas redistributivas, segundo Souza (2014, p. 633), "preveem o atendimento a grupos sociais menos privilegiados, impondo perdas concretas a alguns (que são obrigados a contribuir para a ação, geralmente por meio de impostos) e ganhos incertos a outros (que deveriam se beneficiar da política)". Assim, a natureza que caracteriza o Parfor como política pública redistributiva pode ser constatada no seu gerenciamento financeiro, tendo em vista que o seu financiamento se dá com dinheiro público arrecadado de impostos.

Souza (2014, p. 633-634), ainda nessa linha de pensamento referente a políticas públicas, reafirma que o Parfor pode ser enquadrado como política redistributiva, pois

[...] focaliza grupos sociais específicos, envolvidos tanto na oferta quanto na demanda por qualificação profissional de docentes que atuam na educação básica. Com relação ao embate de forças que permeiam o programa, é possível considerar quatro grupos de interesse: a) os professores das redes estaduais e municipais de educação básica, beneficiados diretamente pelo Plano; b) as instituições que oferecem os cursos e seus professores formadores, agraciados com recursos financeiros para o desenvolvimento das ações de qualificação; c) os órgãos públicos responsáveis pela gestão do Parfor, na disputa por prestígio e recursos dentro do governo; e d) as secretarias estaduais e municipais de educação, beneficiadas politicamente pela melhoria de indicadores de qualificação docente, que tendem a impactar positivamente a percepção de qualidade da educação básica.

Conforme informações do MEC, quando da criação do Parfor, em 2009, previa-se uma oferta superior a 400 mil vagas novas, envolvendo cerca de 150 instituições de educação superior (SCHEIBE, 2010). Os últimos dados disponibilizados pela Capes, em dezembro de 
2019, demonstram os seguintes resultados: 3.043 turmas implantadas até 2019; 100.408 matriculados (de 2009 a 2019); 2.598 turmas concluídas até 2019; 445 turmas em andamento em dezembro/2019; 53.512 professores formados; 59.565 professores cursando em dezembro/2019; 104 IES participantes; 510 municípios com turmas implantadas e 3.300 municípios com professores matriculados (CAPES, 2019).

Como se pode perceber por meio desses dados, o Parfor se configura como uma política de estado de ampla abrangência, articulando diferentes instâncias do poder público, destinado ao enfrentamento de um grave problema da educação no Brasil, no caso, a formação de professores.

\section{O PARFOR na Universidade de Sorocaba - UNISO}

Tendo como referência o quadro global de demanda e oferta de formação docente no país, e do papel do Parfor nesse quadro, a experiência de Sorocaba constitui um caso específico envolvendo uma instituição comunitária: a Universidade de Sorocaba - Uniso. A característica e a vocação comunitária da Uniso podem ser constatadas em sua própria missão:

\footnotetext{
Ser uma Universidade Comunitária que, por meio da integração do ensino, da pesquisa e da extensão, produza conhecimentos e forme profissionais, em Sorocaba e Região, para serem agentes de mudanças sociais, à luz de princípios cristãos (UNISO, 2014, p. 16).
}

A Uniso nasceu em 1951 como Faculdade de Filosofia, Ciências e Letras de Sorocaba - FAFI, oferecendo, a partir de 1954, os cursos de Pedagogia e de Letras Neolatinas. Foi credenciada como Universidade somente em 1994. Em seu processo histórico, sempre direcionou seus esforços na formação de professores. Sorocaba e região testemunham os inúmeros benefícios de uma trajetória acadêmica dedicada ao magistério (UNISO, 2014).

Atualmente, a Uniso mantém 64 cursos de graduação (sendo 12 licenciaturas, 39 bacharelados e 13 tecnológicos); oferece cerca de 200 cursos de pós-graduação "lato sensu", 04 cursos de pós-graduação com mestrado e doutorado, recomendados pela Capes, sendo um deles o Programa de Pós-Graduação em Educação. Ainda mantém um significativo número de cursos, projetos, programas e outras atividades de extensão, voltados ao atendimento da comunidade de Sorocaba e Região.

Dentre esses Projetos, está o Parfor. O Parfor na Uniso nasceu após uma reunião realizada no mês de março de 2010, na Prefeitura Municipal de Mairinque/SP, com os Secretários Municipais de Educação da Região de Sorocaba, a representante do MEC no estado de São Paulo, o presidente da União Nacional dos Dirigentes Municipais de Educação - Undime e representantes da Uniso. Nesse encontro, constatou-se que cerca de 570 docentes 
necessitavam da Licenciatura em Pedagogia e, aproximadamente, 140 docentes precisavam de licenciatura em Música; este último curso, em razão das alterações ocorridas na Lei de Diretrizes e Bases da Educação Nacional - LDBEN, que passara a exigir que o componente curricular Arte englobasse conteúdos obrigatórios de música. Havia também demanda para outras licenciaturas, mas em número bem reduzido.

Diante o exposto, e tendo em vista sua capacidade institucional e a demanda existente cadastrada em plataforma específica da Capes/MEC (por meio da pré-inscrição de profissionais da educação básica da rede pública), a Uniso ofereceu, para o $2^{\circ}$ semestre de 2010, 120 vagas para o curso de Pedagogia e 30 vagas para o Curso de Música. Após processo de validação por parte das secretarias municipais e estadual e processo seletivo interno da Instituição, foram abertas duas turmas do curso de Pedagogia, no período noturno, com 74 alunos matriculados (uma turma com 36 alunos e outra turma com 38 alunos). Para o curso de Música, não houve matrículas em número suficiente para abertura de turma. Vale destacar que houve quantidade significativa de profissionais da educação básica que não tiveram sua pré-inscrição analisada pelas secretarias municipais e estadual de Educação de São Paulo, como também pré-inscrições não validadas, o que fez com que a demanda final ficasse reduzida e permitisse a criação de apenas duas turmas para o curso de Pedagogia.

No $1^{\circ}$ semestre de 2011, foram oferecidas mais 70 vagas para o curso de Pedagogia. Após o cumprimento de todas as fases de análise para abertura de turmas especiais, efetivouse a formação de mais uma turma do curso de Pedagogia, com 31 alunos matriculados no turno noturno.

Em relação à formação de turmas especiais para o curso de Pedagogia no ParforUniso, Pinto e Ferreira (2013, p. 81) acreditam que:

A conjugação dos fatores - oportunidade, gratuidade e experiência de trabalho, direcionou os alunos para o curso de Pedagogia da Uniso, uma das licenciaturas mais conhecidas na cidade e região, respondendo há cinquenta e nove anos pela formação de professores e especialistas que exercem atividade docente ou correlata, nos sistemas educacionais existentes.

\section{O projeto pedagógico do PARFOR-UNISO}

O curso de Pedagogia oferecido pela Uniso no âmbito do Parfor seguiu o mesmo Projeto Pedagógico do curso oferecido pelas turmas regulares da Instituição, o qual foi elaborado em conformidade com a Resolução CNE/CP n ${ }^{\circ} 1 / 2006$, que institui as Diretrizes 
Curriculares Nacionais para os cursos de Pedagogia. Com carga horária de 3.200 horas, o curso foi oferecido de segunda a sexta-feira, no período noturno, em regime presencial.

A disposição dos componentes curriculares na matriz curricular do curso de Pedagogia do Parfor-Uniso também estava em conformidade com o estudo realizado por Gatti (2010), a qual divide a estruturação curricular desses cursos nos seguintes eixos:

- Conhecimentos relativos aos fundamentos teóricos da educação, englobando componentes curriculares, como: Sociologia e Educação, Filosofia da Educação, Filosofia da Educação Brasileira, Psicologia da Educação, Antropologia e Educação, Didática: Teorias e Práticas, História da Educação, História da Educação Brasileira.

- Conhecimentos relativos aos sistemas educacionais, incluindo componentes curriculares, como: Currículo e Cultura, Gestão Educacional, Projetos Pedagógicos, Planejamento e Avaliação Educacional, Supervisão Educacional, Educação e Trabalho Docente.

- Conhecimentos relativos à formação profissional específica, em componentes curriculares, como: Alfabetização, Fundamentos e Metodologia da Educação Infantil, Fundamentos e Metodologia do Ensino de Artes, Fundamentos e Metodologia do Ensino de Geografia, Fundamentos e Metodologia do Ensino de Português, Fundamentos e Metodologia do Ensino de Ciências, Educação e Tecnologia.

- Conhecimentos relativos às modalidades e aos níveis de ensino, incluindo componentes curriculares, como: Educação e Diversidade, Infância e Educação, Educação e Movimentos Sociais, Fundamentos e Metodologia da Educação de Jovens e Adultos. Constata-se aqui, como no estudo de Gatti (2010), que a quantidade de componentes curriculares voltados para a educação infantil também é baixa.

- Conteúdos relacionados à pesquisa e ao Trabalho de Conclusão de Curso (TCC), em componentes curriculares, como: Prática de Pesquisa I, Prática de Pesquisa II e Prática de Pesquisa III.

- Atividades Complementares, no componente curricular: Atividades Teórico-Práticas de Aprofundamento em Áreas Específicas.

- Conteúdos relacionados a outros saberes, em componentes curriculares, como: Cultura, Religiosidade e Mudança Social, Língua Portuguesa: Texto e Contexto, Língua Brasileira de Sinais.

Com base nos conteúdos curriculares elencados, o Projeto Pedagógico do curso de Pedagogia da Uniso almejava um perfil profissiográfico que contemplasse a formação teórica, diversidade de conhecimentos e de práticas que se articulavam ao longo do curso, permitindo que o Pedagogo formado pudesse atuar na:

I. docência em escolas da rede pública e privada, nas modalidades: Educação Infantil, Anos Iniciais do Ensino Fundamental, Educação de Jovens e Adultos;

II. docência em espaços não escolares, na promoção da aprendizagem de sujeitos em diferentes fases do desenvolvimento humano, em diversos níveis e modalidades do processo educativo;

III. gestão das instituições escolares e não escolares, contribuindo para a elaboração, implementação, coordenação, acompanhamento e avaliação do projeto pedagógico; 
IV. assessoria e consultoria, contribuindo na observação, análise, planejamento, implementação e avaliação de processos educativos e de experiências educacionais, em equipes multidisciplinares, em instituições não escolares e em órgãos subregionais, regionais e centrais da administração do sistema de ensino público; e V. produção e difusão do conhecimento científico e tecnológico do campo educacional, por meio da Pesquisa e Iniciação Científica (UNISO, 2009, p. 13).

Mesmo sendo um curso de primeira licenciatura, de formação inicial, o curso de Pedagogia da Uniso no âmbito do Parfor, de acordo com Pinto e Ferreira (2013), estava também estruturado dentro do conceito de educação permanente, vislumbrando a educação como um processo que se estende por toda a vida e entendendo que esse processo se prolonga para além da escola, procurando preparar o professor para participar da vida social, política, cultural e artística, envolvendo a teoria e a prática. Sobre essa última questão, vale mencionar que o Curso tinha $56 \%$ de componentes curriculares teóricos e $44 \%$ de componentes curriculares práticos.

Procurou-se, também, no curso de Pedagogia do Parfor da Uniso, conforme apontam Pinto e Ferreira (2013), a formação de um novo professor, com visão reflexiva, ampla e criativa, apto a atender às necessidades da sociedade, nos contextos da globalização e das realidades política, econômica e social, que diretamente se refletem nas ações e nos papéis da escola e demais instituições formadoras, que também se renovam diariamente. De acordo com Imbernón (2006, p. 12):

Essa necessária renovação da instituição educativa e esta nova forma de educar requerem uma redefinição importante da profissão docente e que se assumam novas competências profissionais no quadro de um conhecimento pedagógico, científico e cultural previstos. Em outras palavras, a nova era requer um profissional da educação diferente.

Nesse contexto, as aulas desenvolvidas no âmbito do Parfor procuraram orientar o aluno professor-cursista a refletir sobre seu trabalho e sua prática na sala de aula e no conjunto da instituição escolar, analisando seus problemas e procurando soluções. Entretanto, não se pode falar apenas do professor reflexivo, mas, também, entende-se como necessária a transformação da escola em uma escola reflexiva, "que tem de ser organizada de modo a criar condições de reflexividade individuais e colectivas. Tem de se pensar a si própria, na sua missão e no modo como se organiza para cumpri-la" (ALARCÃO, 2003, p. 44).

Ao tratar da questão da formação docente e da construção de um perfil de professor e escolas reflexivos, Pinto e Ferreira (2013, p. 83-84) afirmam que:

[...] dentro da formação inicial, o Parfor proporciona a oportunidade da valorização da vivência educativa do professor-aluno, conscientizando-o da importância da reflexão sobre suas práticas. O conhecimento teórico-prático adquirido na universidade contribuirá para o conhecimento da realidade de sua escola, seus problemas específicos, que, estudados com a equipe escolar e fundamentados teoricamente, gerarão novos conhecimentos e poderão tornar o professor mais 
competente para analisar e agir sobre seu cotidiano. Essa estratégia de formação não deverá limitar o docente à resolução de problemas apenas imediatos, mas, sim, deverá visualizá-los na perspectiva mais ampla da sociedade na qual a escola está inserida. O professor reflexivo será mais participativo, consciente de seu papel na construção de um ensino e de uma educação de qualidade.

Nesse contexto, importante se faz mencionar que as aulas ministradas nos componentes curriculares do curso de Pedagogia da Uniso, no âmbito do Parfor, utilizavam metodologias diferenciadas, como: aulas expositivas compartilhadas, seminários, desenvolvimento de projetos e pesquisas, aulas práticas e utilização de metodologias ativas de aprendizagem. Deve-se também destacar que, além das práticas em salas de aula, os alunos do Parfor-Uniso participaram de uma série de atividades externas, como visitas-técnicas ao Museu Paulista, à Creche da Carochinha da Universidade de São Paulo, ao Museu da Língua Portuguesa, ao Museu Afro Brasil, ao Museu Catavento, ao Aquário Municipal de São Paulo, à Bienal do Livro, ao Memorial da América Latina e algumas turmas do Programa de Educação de Jovens e Adultos da Uniso - Proeja. Os alunos do Parfor-Uniso também participaram de uma série de oficinas, como: Produção de Texto, Contação de Histórias, Musicalização na Educação Infantil, Inclusão, Atividades experimentais de Geometria com o Uso do Tangram, Alfabetização e Literatura, Poesia em Sala de Aula, Desafios da Gestão. Houve também diversas palestras realizadas para os alunos do Parfor-Uniso, como: Gestão Democrática na Escola Pública, A Inclusão da História da África na Educação Básica (Lei no 10.639/2003), Ética na Pesquisa, Dificuldades de Aprendizagem na Educação de Jovens e Adultos: um novo olhar para o desenvolvimento humano. Todas essas atividades foram pagas com verba de custeio disponibilizada pela Capes para o desenvolvimento do Programa.

\section{Evasão e alunos formados no PARFOR-UNISO}

O Parfor-Uniso atendeu a um total de 105 alunos, sendo duas turmas no $2^{\circ}$ semestre de 2010 e uma turma no $1^{\circ}$ semestre de 2011 (Quadro 1).

Das duas turmas que ingressaram no $2^{\circ}$ semestre de 2010, a primeira turma, com 36 alunos, apresentou uma evasão de 20 alunos, o que representa uma taxa de 55,56\%. Das três turmas, a primeira foi a que apresentou a maior evasão. Já a segunda turma, composta por 38 alunos, teve uma evasão bem menor, de 14 alunos, com uma taxa de $36,84 \%$. A terceira turma que ingressou no $1^{\mathrm{o}}$ semestre de 2011, com 31 alunos, apresentou uma evasão de apenas 06 alunos, correspondendo a 19,36\% do total de alunos matriculados inicialmente; evasão bem menor, se comparada com as turmas que ingressaram um semestre antes. 
Também chama a atenção o fato de que, em todas as três turmas do Parfor-Uniso, a taxa de evasão é maior do que a média nacional, de 16,53\%, conforme aponta o Relatório de Gestão do Parfor: 2009-2013 (BRASIL, 2013). Em relação à primeira turma do Parfor-Uniso, a taxa de evasão chega a quase quatro vezes mais alta do que a média nacional. Embora a evasão seja uma questão fundamental na avaliação da implementação de políticas públicas, nesse caso específico, faltam informações que permitam compreender o ocorrido. $\mathrm{O}$ fato é que, seguramente, o valor de repasse feito pelo MEC, no valor de $\mathrm{R} \$ 355.000,00$, teria tido impacto maior no sistema de ensino na região, considerando a quantidade de formados.

As duas turmas que ingressaram no $2^{\circ}$ semestre de 2010 se formaram, em sua maioria, em dezembro de 2013. Da primeira turma, 16 alunos concluíram o Curso, o que representa proporção bem menor, se comparada com as turmas que ingressaram um semestre antes; equivale a 44,44\% do total de alunos matriculados inicialmente. Da segunda turma, 24 alunos concluíram o curso, o que equivale a $63,16 \%$ do total de alunos matriculados inicialmente. A terceira turma se formou, em sua maioria, em junho de 2014; o total de alunos formados nessa turma foi de 25 alunos, correspondendo a $80,64 \%$ do total de matriculados inicialmente.

Quadro 1 - Ingressantes, evadidos e formados - Parfor-Uniso

\begin{tabular}{|c|c|c|c|c|}
\hline Curso / Turma & $\begin{array}{c}\text { Semestre/ } \\
\text { Ano }\end{array}$ & $\begin{array}{c}\text { Total de } \\
\text { Ingressantes }\end{array}$ & Evadidos & Formados \\
\hline Pedagogia - Turma A & $2^{\mathbf{o}} / 2010$ & $36(100 \%)$ & $20(55,56 \%)$ & $16(44,44 \%)$ \\
\hline Pedagogia - Turma B & $2^{\circ} / 2010$ & $38(100 \%)$ & $14(36,84 \%)$ & $24(63,16 \%)$ \\
\hline Pedagogia - Turma A & $1^{\circ} / 2011$ & $31(100 \%)$ & $06(19,36 \%)$ & $25(80,64 \%)$ \\
\hline
\end{tabular}

Fonte: Serviço de Atendimento ao Aluno da Uniso (2016)

Em suma, do total de 105 alunos iniciantes, os formados no curso de Pedagogia do Parfor-Uniso totalizaram 65 professores em 2015. Do total de 2.189 docentes da educação básica já formados pelo Programa no Brasil até 2015 (ano em que o Parfor finalizou suas atividades na Uniso), os formados pela Uniso representaram 2,97\%.

\section{O PARFOR-UNISO e seus resultados}

No curso de Pedagogia do Parfor da Uniso, pode-se verificar uma forte relação com as comunidades local e regional, no compromisso com a educação e com os resultados das práticas e dos serviços vinculados ao ensino, à pesquisa e à extensão voltados para essas comunidades. Isso é confirmado por Pinto e Ferreira (2013, p. 81-82), os quais afirmam que:

Os alunos são provenientes de municípios que fazem parte da região administrativa de Sorocaba, como: Votorantim, Piedade, São Roque, Mairinque, Tietê, Araçoiaba da Serra, Itu, Salto, Ibiúna, incluindo a cidade de Sorocaba. Em sua totalidade, 
atuam em classes de Educação Infantil e anos iniciais do Ensino Fundamental $\left(1^{\circ}\right.$ ao $5^{\circ}$ ano). Por essa razão, participam das aulas trazendo como bagagem suas experiências diárias, muitas vezes de longos anos, exigindo dos professores uma atuação diferenciada em todos os componentes curriculares. Assim, para além da oferta da formação inicial, o curso proporciona a oportunidade de valorização da vivência educativa do professor-aluno.

No que se relaciona ao perfil dos alunos do Parfor, pode-se constatar que, na implantação do Programa na Uniso, os alunos professores-cursistas, em sua maioria, desempenhavam atividades de auxiliares de ensino em berçários, creches e outras fases da Educação Infantil. Isso porque, quando da implantação do Parfor, foi autorizado que outros profissionais da educação que não fossem especificamente docentes pudessem se matricular no Curso.

Esses profissionais eram contratados em estabelecimentos de ensino independentemente de suas qualificações serem ou não específicas ao ensino; desempenhavam as atividades sem fundamentação das necessidades e características que envolvem a criança na fase do seu desenvolvimento (0 a 5 anos). Logo, a primeira situação que se apresentou foi a de reconstruir uma prática que se reforçava pela repetição e por ser a única conhecida por esses docentes. Nesse contexto, na perspectiva teórica do Curso, a proposta curricular apresentava uma diversidade de conteúdos que objetivava a compreensão dos fundamentos que devem nortear o profissional e sua prática escolar. Nesse aspecto, componentes curriculares teóricos e práticos se associam de forma inter-relacionada, tanto pela organização dos conteúdos quanto pela realização de atividades constantes na Oficina Pedagógica (laboratório para aulas práticas), nas pesquisas na biblioteca, na confecção de material escolar, na execução de projetos pedagógicos, excursões culturais na cidade, região, interior e capital do estado de São Paulo, visitas às instituições com um cotidiano escolar mais complexo em sua organização, funcionalidade e estruturação, e diferenciado daquele a que estão acostumadas a encontrar em suas funções diárias.

Considerando o projeto pedagógico do Parfor-Uniso, seus objetivos de formação docente e sua estruturação, considerando também as características dos alunos, no âmbito de uma política pública específica, coloca-se como necessário buscar quais foram seus resultados.

A primeira informação que se apresenta refere-se à avaliação do Curso feita pelos alunos. A Comissão Própria de Avaliação - CPA da Uniso realizou em 2013 uma pesquisa sobre como os alunos avaliavam os docentes vinculados em cada um dos componentes curriculares ministrados. Os alunos avaliaram os componentes curriculares e os docentes referentes aos anos de 2012 e 2013. O instrumento de avaliação continha dez questões, cujas 
alternativas de respostas eram: discordo plenamente, discordo, concordo parcialmente, concordo e concordo plenamente.

A primeira questão constante do questionário respondido pelos alunos do Curso indagava se o docente "apresentou a proposta de trabalho para o desenvolvimento dos conteúdos". As respostas indicaram que 37,17\% dos alunos concordaram plenamente e $24,67 \%$ concordaram com esta assertiva; diferentemente, apenas 9,32\% concordaram parcialmente, 3,38\% discordaram e 3,59\% discordaram plenamente. Ou seja, é pequena a proporção dos alunos que entenderam que a proposta do Curso não foi devidamente apresentada e discutida para seu conhecimento. Por outro lado, cumpre destacar que foi de $21,86 \%$ a proporção dos alunos que não responderam a essa questão. Percebe-se, portanto, que $61,84 \%$ dos alunos avaliaram positivamente a apresentação do plano de ensino pelo docente, escolhendo as opções concordo plenamente e concordo.

A segunda pergunta, indagava se o docente "enfatizou a importância dos conteúdos para a sua futura profissão". As respostas indicaram que 37,95\% dos alunos concordaram plenamente com essa afirmação e 22,81\% concordaram. Apenas 10,60\% concordaram parcialmente, $2,35 \%$ discordaram e 3,55\% discordaram plenamente. 22,73\% dos alunos não responderam a essa questão. Percebe-se, portanto, que 60,76\% das respostas avaliaram positivamente o trabalho docente, demonstrando, em suas aulas, a importância do que ensinavam para a profissão do pedagogo formado pelo Curso. Também aqui chama a atenção a proporção dos que não responderam a essa questão, que foi de $22,73 \%$.

$\mathrm{O}$ terceiro quesito indagava se o professor "utilizou metodologias didáticopedagógicas adequadas, aproveitando adequadamente o tempo da aula ou encontro". Também, aqui, pode-se constatar que $35,56 \%$ dos alunos concordaram plenamente com isso e $23,31 \%$ concordaram. Os restantes, $11,10 \%$, concordaram parcialmente, 3,67\% discordaram e $4,62 \%$ discordaram plenamente. Não responderam a essa questão $21,74 \%$ dos alunos. Aqui também foi possível verificar que a maioria dos alunos, correspondente a 58,87\%, avaliou positivamente as metodologias de ensino adotadas pelos professores, utilizando de modo adequado o tempo para abordar os conteúdos em aula.

A quarta questão perguntava se o docente "esclareceu os critérios de avaliação, utilizou instrumentos de avaliação adequados e diversificados e divulgou com clareza os resultados". Pôde-se verificar que 34,08\% dos alunos concordaram plenamente com esse quesito e 24,50\% concordaram. Assim como nos demais quesitos apresentados até o momento, mais da metade dos alunos $(58,58 \%)$ avaliou positivamente essa questão, afirmando que os docentes possuíam critérios bem definidos de avaliação, divulgando de 
forma objetiva os resultados aos discentes. Diferentemente, 10,73\% concordaram parcialmente, 3,92\% discordaram e 3,80\% discordaram plenamente com as formas de avaliação utilizadas. Os alunos que não responderam a essa questão corresponderam a $22,98 \%$.

A quinta questão tinha por objetivo verificar se o docente "demonstrou que preparou as aulas ou encontros, evidenciou domínio do conteúdo e utilizou linguagem acessível. Constatou-se que $38,94 \%$ dos alunos concordaram plenamente com essa assertiva e $22,40 \%$ concordaram. Apenas 8,79\% concordaram parcialmente, 3,92\% discordaram e 3,92\% discordaram plenamente. Os que não responderam a essa questão totalizaram 22,03\%. Percebe-se, aqui, também, que a maioria dos alunos $(61,34 \%)$ avaliou positivamente esse quesito, evidenciando que os professores preparavam as aulas, tinham domínio dos conteúdos ensinados e o faziam mediante uma linguagem adequada.

A sexta questão indagava se o professor "promoveu atividades que estimularam a participação dos alunos, inclusive em atividades extraclasse, orientando adequadamente os alunos". Também, aqui, 31,97\% dos alunos concordaram plenamente com essa questão e $24,30 \%$ concordaram. Diferentemente, $12,38 \%$ concordaram parcialmente, 4,66\% discordaram e 3,96\% discordaram plenamente. Não responderam a essa questão $22,73 \%$ dos alunos. Percebe-se, novamente, que a maioria dos alunos, o equivalente a 56,27\%, avaliou positivamente os docentes no estímulo à participação dos alunos nas atividades propostas.

A sétima questão perguntava se o professor "relacionou-se com os alunos de forma adequada e imparcial". Pôde-se observar que 39,44\% dos alunos concordaram plenamente com esse quesito e 24,05\% concordaram. Apenas 7,47\% concordaram parcialmente, 2,64\% discordaram e $3,51 \%$ discordaram plenamente. Os que não responderam a esta questão totalizaram 22,90\%. Pôde-se notar que porcentagem de $63,49 \%$ dos alunos avaliou positivamente essa questão, acreditando que os professores que ministraram aulas se relacionavam com os alunos de maneira adequada, tratando igualmente a todos.

A oitava questão indagava se o docente "foi acessível aos questionamentos dos alunos". Verificou-se que 39,73\% dos alunos concordaram plenamente e 22,85\% concordaram. Assim, também nesse quesito, a maioria (62,58\%) avaliou positivamente a forma como os professores se portaram diante das dúvidas dos alunos. Diferentemente, 7,43\% concordaram parcialmente, $3,26 \%$ discordaram e 3,84\% discordaram plenamente. Os que não responderam a esse questionamento corresponderam a $22,90 \%$ do total de alunos.

A nona questão procurou verificar se o professor "estimulou atividades que propiciaram a autoaprendizagem dos alunos". Constatou-se que 34,94\% dos discentes 
concordaram plenamente e $23,64 \%$ concordaram. Seguindo a mesma tendência das demais questões, aqui, também, a maioria avaliou positivamente esse quesito $(58,58 \%)$. Entretanto, $10,60 \%$ concordaram parcialmente, $3,22 \%$ discordaram e 4,08\% discordaram plenamente. A porcentagem de alunos que não responderam a essa questão foi de 23,51\%.

Por fim, o décimo questionamento procurou verificar se o docente "demonstrou conhecimento do projeto do curso e da Instituição". Constatou-se que 38,24\% dos alunos concordaram plenamente com essa afirmação e 24,42\% concordaram; a proporção dos que fizeram uma avaliação nesse quesito correspondeu a 62,66\%. Do restante, 8,33\% concordaram parcialmente, 2,23\% discordaram e 3,22\% discordaram plenamente. Os que não responderam a essa questão atingiram $23,56 \%$ dos alunos.

Pode-se perceber, pelo questionário aplicado e as respostas obtidas, que, em todas as questões, a porcentagem de avaliações positivas, considerando apenas as opções "concordo plenamente" e "concordo", foi de aproximadamente $60 \%$, superando em proporção bastante significativa a porcentagem de avaliações negativas, em torno de 15\%. Mesmo levando-se em conta a proporção significativa de ausência de respostas, a baixa proporção dos que apresentaram restrições permite inferir que o Parfor-Uniso foi bem sucedido, segundo o olhar dos alunos.

Embora informações desse tipo sejam importantes e necessárias para a avaliação de programas desse tipo, pouco ou nada dizem a respeito dos seus impactos.

Um fato que chama a atenção, nessa questão, é que durante todo o processo de vigência do Parfor-Uniso, a "avaliação" do Programa se deu apenas por meio da prestação de contas anuais, quando a Capes analisava se os recursos investidos e repassados às Instituições estavam sendo bem empregados. Em nenhum momento, houve um processo de avaliação in loco do Programa, realizado por comissão de especialistas designados especialmente para esse fim, nos moldes do que prevê o Sistema Nacional de Avaliação da Educação Superior Sinaes. A única avaliação dos alunos do Parfor foi a do Exame Nacional de Desempenho dos Estudantes - Enade, com os demais alunos do curso regular de Pedagogia da Universidade. O curso de Pedagogia da Uniso obteve Conceito Enade 4, mas esse resultado não permite uma análise isolada do Programa, tendo em vista que todos os alunos foram avaliados no conjunto do Curso na Instituição (alunos regulares mais alunos do Parfor).

Assim, pouco ou nada se sabe sobre o que a realização do Curso representou para os alunos, para a melhoria de suas qualificações profissionais e para a melhoria do seu trabalho como educador, além daquilo que o levantamento realizado pela CPA/Uniso forneceu. A CAPES chegou a realizar uma pesquisa com os alunos do Parfor, mas os resultados dessa 
pesquisa não foram divulgados à Universidade para que pudessem ser realizadas reflexões sobre uma política pública tão significativa para a formação de professores no Brasil.

\section{Custeio do curso e prestação de contas}

Da implantação do Parfor-Uniso até sua finalização, anualmente a Uniso realizava a Prestação de Contas à Capes sobre os recursos de custeio e de capital recebidos e utilizados. As verbas de custeio eram repassadas para gastos com material de consumo utilizado pelas turmas implantadas, diárias, obrigações tributárias e contributivas, serviços prestados por pessoas físicas e jurídicas, viagens técnicas, rateio de despesas de energia, água e esgoto, correios e telefone, bem como rateio de despesas com setores administrativos da Universidade. Já as verbas de capital eram destinadas à aquisição de equipamentos e livros para a bibliografia utilizada nos componentes curriculares e indicadas nos Planos de Ensino dos docentes-bolsistas.

Vale destacar que as despesas com bolsas de estudo pagas aos docentes que ministravam as aulas e aos coordenadores geral e do curso de Pedagogia do Parfor não se enquadravam nem em despesas de custeio nem em despesas de capital, sendo pagas diretamente pela Capes aos bolsistas, em contas abertas exclusivamente para essa finalidade.

Comparando-se o valor total dos repasses realizados pela Capes para a execução do Programa, correspondente a $\mathrm{R} \$ 355.000,00$, mais o valor total dos rendimentos em poupança obtidos durante o período de vigência do Parfor na Uniso, de R $\$ 19.189,59$, obteve-se um saldo de $\mathrm{R} \$ 374.189,59$ de investimentos para a execução e desenvolvimento das três turmas. Comparando-se com o valor total utilizado pela Universidade para as despesas de custeio e de capital, de $\mathrm{R} \$ 152.112,77$, constata-se que a Uniso usou menos da metade da verba disponibilizada, o que equivale, apenas, a $42,85 \%$ do montante total repassado pela Capes. Esses dados chamam a atenção para a avaliação do grau de eficácia do Programa, quando variáveis, como a evasão, são altas.

\section{Considerações finais}

No que tange à formação de professores da educação básica no Brasil, problemas históricos ainda se perpetuam no presente, principalmente no que se refere ao déficit de docentes para atuarem nesse nível de ensino, a ausência de formação inicial e continuada desses profissionais e a falta de atratividade da carreira docente, marcada em grande parte pela jornada excessiva de trabalho e pela baixa remuneração da profissão. Para sanar ou, ao 
menos, amenizar esses problemas, vêm sendo adotadas, nos últimos tempos, políticas públicas, tais como a Política Nacional de Formação de Professores para a Educação Básica, com ações como o Programa Nacional de Formação de Professores para a Educação Básica Parfor.

Em âmbito nacional, o Parfor constitui uma política pública de Estado importante para o país, ao garantir que os professores em exercício na rede pública de educação básica tenham acesso à formação exigida pela LDBEN, beneficiando não somente os docentes, mas também as secretarias de educação dos estados e municípios e as IES participantes.

Relevante se faz destacar que o Parfor oferece condições de acesso, para que os docentes possam adquirir a formação exigida pela LDBEN, mas pouco se faz para a permanência dos docentes da educação básica pública (alunos) no Programa. Somente após algum tempo de sua implementação é que a Capes permitiu a utilização dos recursos das verbas de custeio repassados às IES para auxílio a esses docentes em despesas de transporte e alimentação, dentre outras. Além disso, os docentes participantes do Programa não têm sua jornada de trabalho alterada para participarem do Parfor, não sendo dispensados de nenhuma de suas atividades nas escolas. Essa questão, no entanto, não depende apenas de decisões da Capes, mas esbarra nas legislações estaduais e municipais, e também depende da vontade política das secretarias de educação desses estados e municípios. Esses fatores contribuem para a alta taxa de evasão do Plano, equiparável ao índice de evasão nacional da educação superior.

Em termos avaliativos, constata-se que, até o momento, não houve uma avaliação específica dos cursos oferecidos no âmbito da política pública Parfor por meio do governo federal, nos moldes do que ocorre com outros cursos superiores, dentro do Sinaes. Os alunos dos cursos de licenciatura do Parfor oferecidos pelas IES participantes do Programa apenas foram avaliados no Enade, porém os resultados desses alunos foram divulgados com os dos alunos de cursos de licenciatura regulares dessas Instituições, não permitindo, assim, uma análise apropriada da política. Também não se observa uma avaliação mais minuciosa da política em termos de melhoria da qualidade da educação superior do país, do desempenho dos docentes da educação básica que foram formados pelo Programa e da utilização dos recursos disponibilizados para a efetivação do Parfor. Há, apenas, prestações de contas anuais por parte das IES e a divulgação de um Relatório de Gestão 2009-2013 da Capes, em que se observa também uma prestação de contas à sociedade, com informações muito mais quantitativas do que qualitativas. 
No âmbito da Uniso, a implantação do Parfor se deu em um momento em que as instituições comunitárias do Estado celebraram convênios com a Capes, principalmente em razão de as IES públicas não terem participado inicialmente do Programa. Nesse sentido, essas instituições comunitárias tiveram papel importante na concretização e na participação do estado de São Paulo no Parfor.

Os problemas encontrados na implantação e efetivação do Parfor na Uniso em muito se assemelham àqueles encontrados em âmbito nacional. Quando de seu início, o Plano teve grande participação das secretarias estadual e municipais de educação de Sorocaba e região, o que permitiu a abertura de duas turmas especiais em 2010 e uma turma em 2011, no curso de Pedagogia. No entanto, nos anos seguintes, essa participação foi diminuindo, sendo que muitos profissionais interessados em uma vaga no Parfor da Uniso acabaram não sendo validados ou não tendo sua inscrição ao menos analisada por essas Secretarias, o que não viabilizou a abertura de novas turmas.

Constata-se que o Parfor da Uniso abriu a possibilidade de acesso ao nível superior dos profissionais da educação básica de Sorocaba e região, mas as condições para a permanência no curso ainda foram limitadas, restringindo-se apenas à ajuda com transporte pelas Prefeituras Municipais de cidades da região. Não havia, assim como no âmbito nacional, redução de jornada de trabalho e dispensa de atividades na escola para que o docente da educação básica pudesse frequentar as aulas no curso de Pedagogia, em função das legislações estadual e municipais.

A avaliação feita pelos discentes quanto ao trabalho dos docentes que ministraram aulas no Parfor-Uniso indica que, de modo geral, eles foram muito bem avaliados em quesitos como: reforçar a importância dos conteúdos ministrados para a futura profissão do aluno; utilizar metodologias didático-pedagógicas adequadas, aproveitando adequadamente o tempo da aula ou encontro; promover atividades que estimulam a participação dos alunos, inclusive em atividades extraclasse; orientar adequadamente os alunos; ser acessível aos questionamentos dos alunos; e estimular a atividades que propiciam a autoaprendizagem dos alunos.

Assim, pelo exposto, pode-se concluir que a implantação do Parfor na Uniso veio atender às políticas públicas atualmente existentes, principalmente no tocante à formação de docentes da educação básica, demonstrando uma colaboração produtiva, voltada para o interesse comunitário, regional e social, por meio da parceria entre a Universidade e o setor público. 


\section{Referências}

ALARCÃO, Isabel. Escola reflexiva e nova racionalidade. Porto Alegre: Artmed, 2003.

BELLONI, Isaura; MAGALHÃES, Heitor de; SOUSA, Luzia Costa de. Metodologia de avaliação em políticas públicas: uma experiência em educação profissional. 2. ed. São Paulo: Cortez, 2001.

BRASIL. Ministério da Educação. Coordenação de Aperfeiçoamento de Pessoal de Nível Superior - CAPES. Diretoria de Formação de Professores da Educação Básica - DEB.

Relatório de Gestão Parfor: 2009-2013. Brasília, DF: CAPES, 2013.

BRASIL. Ministério da Educação. Decreto n ${ }^{\circ}$ 8.752, de 9 de maio de 2016. Dispõe sobre a Política Nacional de Formação dos Profissionais da Educação Básica. Diário Oficial da União, Brasília, DF, 10 maio 2016.

BRASIL. Ministério da Educação. Sistema Integrado de Planejamento, Orçamento e Finanças do Ministério da Educação - SIMEC. Apresentação. Brasília, DF: MEC, 2019.

CAPES. COORDENAÇÃO DE APERFEIÇOAMENTO DE PESSOAL DE NÍVEL SUPERIOR. Plano Nacional de Formação de Professores da Educação Básica -

PARFOR. Dez. 2019. Disponível em: http://www.capes.gov.br/pt/educacao-basica/parfor.

Acesso em: 20 dez. 2019.

FILIZOLA, Paula. Secretarias podem pedir cursos de formação para professores. Brasília, DF: MEC, 2012. Disponível em: http://portal.mec.gov.br/ultimas-noticias/225sistemas-1375504326/18097-secretarias-podem-pedir-cursos-de-formacao-para-professores. Acesso em: 15 dez. 2019.

FRANTZ, Walter; SILVA, Enio Waldir da. As funções sociais da universidade: o papel da extensão e a questão das comunitárias. Ijuí: Unijuí, 2002.

GATTI, Bernardete A. Formação de professores no Brasil: características e problemas. Educação \& Sociedade, Campinas, v. 31, n. 113, p. 1355-1379, dez. 2010. Disponível em: http://www.scielo.br/scielo.php?script=sci_arttext\&pid=S010173302010000400016\&lng=en\&nrm=iso. Acesso em: 20 abr. 2019.

GATTI, Bernardete Angelina; BARRETO, Elba Siqueira de Sá; ANDRÉ, Marli Eliza Dalmazo de Afonso. Políticas docentes no Brasil: um estado da arte. Brasília: Unesco, 2011.

IMBERNÓN, F. Formação docente e profissional: formar-se para a mudança e a incerteza. São Paulo: Cortez, 2006.

PESSOA, Izabel Lima; ARAÚJO, Ninna Carla Zamariolli. Educação básica: o Parfor em questão. In: ABDALLA, Maria de Fátima Barbosa; MAIMONE, Fábio Cardoso; MOREIRA, Marly Saba (orgs). Caderno Parfor: da política de formação PARFOR às práticas pedagógicas, experiências e saberes no ensino e na pesquisa. Santos: Leopoldianum, 2013. 
PINTO, Rafael Ângelo Bunhi; FERREIRA, Valdelice Borghi. A implantação do Plano Nacional de Formação de Professores (Parfor) em uma universidade comunitária. Revista de Educação do Cogeime, Piracicaba, ano 22, n. 42, p. 71-85, jan./jun. 2013.

RISTOFF, Dilvo I.; BIANCHETTI, Lucídio. A pós-graduação e suas interlocuções com a educação básica: (Des)encontros históricos e manutenção do apartheid socioeducacional. Avaliação: Revista da Avaliação da Educação Superior, Campinas; Sorocaba, SP, v. 17, n. 3, nov. 2012. Disponível em: http://www.scielo.br/scielo.php?script=sci_arttext\&pid=S141440772012000300010\&lng=pt\&nrm=iso. Acesso em: 2 abr. 2019.

SCHEIBE, Leda. Valorização e formação dos professores para a educação básica: questões desafiadoras para um novo Plano Nacional de Educação. Educação \&

Sociedade, Campinas, v. 31, n. 112, p. 981-1000, set. 2010. Disponível em:

http://www.scielo.br/scielo.php?script=sci_arttext\&pid=S0101-

73302010000300017\&lng=en\&nrm=iso. Acesso: 20 abr. 2019.

SOUZA, Valdinei Costa. Política de formação de professores para a educação básica: a questão da igualdade. Revista Brasileira de Educação, Rio de Janeiro, v. 19, n. 58, p. 629653, jul./set. 2014. Disponível em:

http://www.scielo.br/scielo.php?script=sci_arttext\&pid=S1413-

24782014000800006\&lng=en\&nrm=iso. Acesso em: 15 abr. 2019.

UNISO. UNIVERSIDADE DE SOROCABA. Projeto Político-Pedagógico do Curso de Pegagogia - Licenciatura. Sorocaba: Uniso, 2009.

UNISO. UNIVERSIDADE DE SOROCABA. Resolução Consu no 049/14. Aprova Plano de Desenvolvimento Institucional - PDI 2015-2019 da Universidade de Sorocaba. Sorocaba: Uniso, 2014.

VANNUCCHI, Aldo. A universidade comunitária. São Paulo: Loyola, 2004. 